\title{
RECURSOS FINANCEIROS PÚBLICOS E PRIVADOS EM EQUIPES ESPORTIVAS PROFISSIONAIS: O CASO DO BASQUETEBOL DE LONDRINA (1997-2004)
}

Edson Hirata,

Luiz Alberto Pilatti

\section{Resumo}

O objetivo desse estudo foi verificar em que medida os recursos financeiros que mantêm equipes esportivas são oriundos da iniciativa privada e do poder público. A venda de ingressos foi responsável por cerca de dois por cento das receitas, a venda de direitos de transmissão não gerou recursos algum e o patrocínio foi apontado como o principal responsável pela captação de recursos do basquetebol de Londrina. Os recursos financeiros oriundos do poder público foram significativos de tal monta que pôdese concluir que a manutenção da equipe de basquetebol de Londrina direta ou indiretamente aconteceu em função do poder público.

\section{Palavras-Chave}

Espetacularização do basquetebol; Políticas públicas para o esporte; Basquetebol.

PUBLIC AND PRIVATE FINANCIAL RESOURCES IN PROFESSIONAL SPORTIVE TEAMS: THE CASE Of LONDRINA BASKETBALL (1997-2004)

Edson Hirata,

Luiz Alberto Pilatti

\begin{abstract}
This study aimed to verify how the financial resources that keep sportive teams derive from the private initiative and the government. Tickets sale was responsible for about two percent of incomes, while sale of transmission rights didn't provide any resources and the sponsorship was pointed as the main responsible for getting resources for the Londrina's basketball. The financial resources provided by the government were so meaningful that it could be concluded that the maintenance of Londrina's team happened directly or indirectly due to government resources.
\end{abstract}

\section{Key-Words}

Spectacularization of basketball; Public policies for sport; Basketball. 


\section{INTRODUÇÃO}

A indústria do entretenimento encontrou no esporte um de seus principais produtos a serem mercantilizados. Em função das possibilidades de espetacularização, o esporte profissional tornou-se um dos segmentos mais atraentes para os investidores.

Todavia, nem todas as entidades ligadas ao esporte se prepararam para sobreviver em um meio capitalista. Essa observação pode ser notada em boa parte das modalidades esportivas do Brasil que têm dificuldade para conduzir suas atividades com poucos recursos financeiros.

Os administradores do meio esportivo geralmente exploram três principais fontes de receita para gerenciar as suas equipes: a venda de ingressos, a venda de direitos de transmissão e o patrocínio (KEARNEY, 2003). O estudo apresenta inicialmente o pensamento de estudiosos sobre as potencialidades e fragilidades desses três instrumentos fomentadores de receitas, bem como a atuação do poder público nesse contexto.

Tratando-se de um estudo de caso, na seqüência, o texto revela dados empíricos ligados ao basquetebol de Londrina. A supremacia do Londrina Basquete Clube (LBC) no Estado do Paraná, no período de 1997 a 2004, época em que faturou todos os títulos estaduais e em que participou dos Campeonatos Nacionais de Basquetebol Masculino (CNBM) com resultados intermediários, e a sua tradição em levar grandes quantidades de espectadores aos ginásios, justificam a análise dessa equipe.

O objetivo do estudo é verificar em que medida os recursos financeiros que mantêm equipes esportivas profissionais são oriundos da iniciativa privada e do poder público.

\section{AS RECEITAS TRADICIONAIS DO ESPORTE PROFISSIONAL}

Para se entender as origens dos recursos financeiros que custeiam as equipes esportivas profissionais fazse necessário compreender inicialmente que a venda de ingressos, a venda de direitos de transmissão e imagens e o patrocínio são consideradas as categorias tradicionais de arrecadação, bem como as mais importantes. (KEARNEY, 2003). Diagnosticar como a literatura científica enxerga essas três categorias de levantamento de recursos financeiros será o intento inicial desse estudo. 
Uma pesquisa de A.T. Kearney (2003) aponta que no ano de 2001, US\$ 24,8 bilhões foram arrecadados em espetáculos esportivos através da venda de ingressos. Isso equivaleu a 44,76\% do total das receitas daquele ano. Kearney (2003) cita o exemplo do clube de futebol inglês Manchester United, que fatura mais com essa fonte de renda do que com a soma da venda de direitos de transmissão e o patrocínio.

O incremento da venda de ingressos advém do mercado de camarotes VIP nos estádios, como Kearney (2003, p.38) relata:

“Na NFL, liga de futebol americano, há camarotes 'corporativos' que empresas alugam por até US\$150 mil anuais em contratos de cinco a dez anos de locação. Com níveis de lotação próximos de $90 \%$, esses camarotes têm uma demanda que está longe de diminuir.”

Também são oferecidas opções mais simples, como os camarotes comuns, onde o espectador tem um espaço considerável para se acomodar, pode usufruir do serviço de bar e desfruta de uma ótima vista do campo. Nessa opção, o preço médio dos ingressos cresceu mais de 60\% (KEARNEY, 2003, p. 38).

\footnotetext{
A receita com ingressos, contudo, só aumentará se a demanda persistir, e as pessoas só continuarão comprando enquanto extraírem valor dos ingressos. Ao elevar os preços, as organizações esportivas mudaram o perfil do público freqüentador de estádios e ginásios. O novo consumidor de esportes é um torcedor disposto a pagar por uma proposta de valor. Para satisfazê-lo, as empresas esportivas abraçam uma filosofia consagrada há tempos no setor de entretenimento: oferecem pacotes completos de lazer. As arenas esportivas deixaram de ser um amontoado de assentos ao redor de um campo ou quadra - são plataformas de marketing multimídia. Em vez de apenas ver uma partida, o torcedor 'recebe' diversão antes, durante e depois do jogo.
}

Embora esse novo contingente de torcedores seja um dos principais alvos das organizações esportivas, é importante que as mesmas não negligenciem o público tradicional, aqueles torcedores fiéis que gastam seu suado dinheiro para acompanhar o campeonato inteiro, ano após ano, pois nenhum novo nicho de consumidor vale o risco de perder os torcedores tradicionais.

Nos Estados Unidos, os times investiram em vendas de ingressos para empresas e de carnês para a temporada completa, para combater a baixa rentabilidade da venda dos ingressos. Menos da metade do valor do ingresso chega às mãos dos times, devido à intermediação de empresas nessas vendas. (KEARNEY, 2003). 
Para entender a realidade do esporte profissional brasileiro em relação à venda de ingressos, o estudo de Istvan Karoly Kasznar (1999), "O esporte como indústria: solução para criação de riqueza e emprego", parece ser uma referência interessante. $\mathrm{O}$ pesquisador aponta um problema no Voleibol, constatando que o número de pagantes nas Superligas é baixo, mesmo com indicadores de alta potencialidade de mercantilização da modalidade. $17,57 \%$ da população brasileira está propensa a pagar para assistir o voleibol, deixando a modalidade atrás somente do futebol, com 45,36\%, e pouco à frente do basquetebol, com $13,03 \%$.

A incoerência entre o potencial vislumbrado por esse levantamento estatístico e a realidade provoca o surgimento de uma questão inquietante colocada pelo pesquisador:

[...] se o preço de entrada nos estádios é muito barato, como é mesmo, o que estaria impedindo um faturamento melhor? Mais, ainda: se o interesse pelo esporte é tão alto quanto afirmam os dados do Ibope, como podemos aceitar que haja tão diminuto público pagante? (KASZNAR, 1999, p. 68)

O autor aponta ainda, resumidamente, três fatores que podem explicar boa parte dessa situação:

Primeiro, a infra-estrutura dos estabelecimentos esportivos não é atraente para o público pagante de primeira classe. A maioria dos ginásios não foram projetados e construídos pensando no conforto dos espectadores, pois geralmente não existem poltronas, o sistema de ventilação e refrigeração é inadequado e a manutenção ineficaz deixa o ambiente com ares de abandono.

Segundo, os serviços oferecidos como limpeza, vendas de bebidas e alimentos, estacionamentos, policiamento, e atrações são de baixa qualidade e acabam afastando os amantes das arenas esportivas.

Terceiro, a baixa renda da população inibe o consumo de bens, serviços e lazeres esportivos. Parece que esse é um dos fatores que mais limitam a transferência do modelo proposto por Kearney para o Brasil. Afinal, um país em que mais de 63\% das famílias recebem menos de cinco salários mínimos (IBGE, 1999) e dependem do assistencialismo governamental para ter acesso à alimentação e uma parcela, não menos significativa, sobrevive com um salário mínimo, a possibilidade de acesso aos espetáculos esportivos e seus derivados é remota. 
Essas considerações possivelmente sejam válidas para interpretar o caso do basquetebol também. Se existem pontos de distinção entre as realidades das duas modalidades, as similitudes parecem ser preponderantes em muitos aspectos.

De acordo com Keraney (2003), o segundo maior gerador de receitas dentro do esporte profissional é a venda de direitos de transmissão, que foi responsável, em 2001, por cerca de $30 \%$ das receitas desse segmento. Entretanto, algumas mudanças vão influenciar sobremaneira esse tipo de negócio.

Os contratos de longo prazo estão destinados a desaparecer, em virtude da escassez dos dólares do mercado publicitário e da percepção de que os direitos de transmissão estão superestimados. Vislumbrando a possibilidade de ter prejuízo, as principais redes estão desistindo desses contratos para não perder dinheiro. A TV aberta tem se preocupado em transmitir apenas os principais eventos e jogos. Os demais têm chegado ao telespectador através das redes de TV a cabo (KEARNEY, 2003).

Os canais por assinatura, distintamente da TV aberta, não dependem da receita publicitária. Assim, os clubes esportivos e os times profissionais podem aumentar seu faturamento vendendo jogos e eventos para essas emissoras.

A previsão é de que os contratos de transmissão sejam cada vez mais curtos, e uma das tendências é a utilização de estratégias arriscadas por parte das emissoras.

\begin{abstract}
Na próxima temporada, a NBC [emissora de TV americana] vai trocar o prestigiado basquete da NBA pelo arena football [futebol americano de quadra, disputado numa área quatro vezes menor do que um campo tradicional]. A rede de TV nada pagará pelos direitos de transmissão, dividindo riscos e receitas com os times da nova modalidade. Como parte interessada no desenvolvimento desse esporte, a NBC assumiu a possibilidade de atrair o público com o perfil desejado (KEARNEY, 2003, p. 44).
\end{abstract}

Diante da perspectiva da diminuição da renda proveniente da venda dos direitos de transmissão, os dirigentes procuram novos nichos no mercado de distribuição de conteúdo, e aparentemente o mercado digital pode aparecer como uma das alternativas. A Internet pode se tornar um dos protagonistas nesse novo cenário, uma vez que os torcedores utilizam esse meio para se informar sobre os principais acontecimentos de seus times e ídolos, tanto que as páginas esportivas posicionam-se entre as mais visitadas do meio virtual. 
Além da Internet, outras opções estão sendo implementadas. A NBA pretende vender imagens digitais para os seus torcedores, que poderão escolher em que aparelho eletrônico vão recebê-las. A NFL, Liga Profissional de Futebol Americano, por sua vez, está convertendo 32 mil quilômetros de fitas de vídeo para o formato digital, onde os consumidores poderão escolher a imagem por tipo de jogada, pelo nome do atleta ou por outras categorias. O Dallas Mavericks pretende instalar monitores conectados à Internet nos assentos do seu ginásio para que os torcedores possam comprar replays instantâneos e outros produtos diretamente de suas poltronas. Os serviços de mensagens instantâneas devem ser uma das estrelas dessa nova era, e o Manchester United foi um dos pioneiros a usá-los, pois oferece um serviço em que "a cada gol do time, uma mensagem é enviada para o celular de quem pagou pelo serviço" (KEARNEY, 2003, p. 43-44).

Independente da plataforma que as organizações escolham para vender seus produtos, Kearney (2003) ressalta que o fundamental para se aumentar a receita é atrair mais público, e para isso é imprescindível conquistar novas fronteiras. Uma das maneiras utilizadas pela NBA para concretizar essa conquista foi a atração de talentos de todo o planeta para seu mercado. A Fórmula 1 e a Copa do Mundo de Futebol também são bons exemplos da preocupação dos dirigentes esportivos em aumentar as fronteiras de potenciais consumidores de espetáculos esportivos.

O terceiro setor que tradicionalmente proporciona rendimentos aos times profissionais e aos clubes é o patrocínio, que participou com 26,17\% do total arrecadado pelo esporte profissional em 2001. Essa categoria sempre foi primordial para a sobrevivência dos esportes profissionais, entretanto, foi apenas nas duas últimas décadas que a indústria do patrocínio esportivo explodiu.

No Brasil, é comum a prática de empresas públicas, prefeituras e governos estaduais patrocinarem determinadas modalidades ou clubes. Um relato interessante a esse respeito foi dado pelo jornalista esportivo Juca Kfouri (1995) durante o Seminário Indesp de Marketing Esportivo ao ser indagado sobre a postura das empresas públicas ao patrocinar o esporte de alto rendimento. O jornalista utilizou o exemplo da relação entre o Banco do Brasil e o Voleibol para construir seus argumentos. Apesar de entender a importância que esse relacionamento teve no rejuvenescimento da imagem do banco, no bom resultado no ponto de vista de propaganda e marketing e até financeiro, defende que a função principal do banco teria que ser social. 
O BB [Banco do Brasil] tem que estar, ainda hoje, preocupado com a base desse país; com um investimento na formação do nosso esportista ou na saúde do nosso deficiente físico, ou na saúde do nosso trabalhador de terceira idade, muito mais do que com o esporte de alto rendimento". (KFOURI, 1996, p. 50)

Logicamente essa linha de pensamento não é unânime, e caso fosse, grande parte dos esportes amadores estariam fadados ao esquecimento no Brasil.

Os patrocinadores estão determinados a incentivar as modalidades que possibilitem identificação entre o público e a sua marca ou produto, mesmo sem quantificar o retorno sobre o investimento. No entanto, essa prática está sendo posta de lado, substituída pela cobrança de uma prestação de contas do patrocínio com o intuito de auxiliar as empresas a compreender como o patrocinado pode contribuir para atingir seus objetivos.

\section{METODOLOGIA}

O presente estudo é caracterizado como exploratório. O procedimento técnico empregado é o do estudo de caso e para a coleta de dados, utilizou-se como instrumento a entrevista semi-estruturada. Foram ouvidos cinco dirigentes esportivos ligados ao basquetebol londrinense. As entrevistas com os dirigentes esportivos foram gravadas, transcritas e os entrevistados consentiram, por escrito, com a utilização desse material para fins acadêmicos. Os depoimentos dos dirigentes foram codificados, para garantir anonimato aos atores, como Dirigente A, B, C, D e E. A análise de conteúdo foi o procedimento empregado para pinçar fragmentos da percepção dos envolvidos no cotidiano da equipe em exame.

\section{O CASO DO BASQUETEBOL DE LONDRINA}

A idéia de espetáculo possibilita múltiplos ângulos de leituras. Dois deles, talvez os mais evidentes sejam o do artista e do espectador. Pensando no espectador, depara-se com um cenário novo, produzido contemporaneamente com requinte e sofisticação.

O espetáculo, pregam autores como Kearney (2003) e Pilatti (2006), está chegando nos limites da customização. Com efeito, o conforto oferecido ao cliente transcende o desejável, é algo quase que obrigatório.

Focando no objeto em exame, percebe-se que o que se teoriza está muito distante da realidade. Um exemplo é a idéia de camarote, que o dirigente A lembra que ainda não havia sido criado pela equipe de 
Londrina. Esses camarotes poderiam dar mais conforto aos espectadores que quisessem dispender uma quantia maior de dinheiro por esse luxo e aumentar a arrecadação da equipe. De acordo com o Dirigente A, em 2004, só existia um camarote para a diretoria de patrocinadores e autoridades.

A atitude de criar um camarote para os patrocinadores demonstra a correta preocupação que se deve ter com parceiros, todavia, os camarotes só gerarão receitas adicionais para o basquetebol londrinense a partir do momento em que eles forem vendidos ao público.

Não existem opções para os torcedores. O dirigente A comenta que existiam apenas dois tipos de preços de ingressos: o ingresso normal, que custava seis reais e o meio ingresso, que era vendido para os estudantes credenciados ao preço de três reais. Contudo, essas alternativas não denotavam nenhum tipo de serviço adicional.

Intentando melhorar o espetáculo, os dirigentes do LBC procuravam providenciar atrações para entreter o público nos intervalos, como sugerido por Proni (1998). O dirigente A relata o modo como isso se procedia:

[...] a gente sempre aproveita o máximo o torcedor, porque a gente tem muita família, muita criança, pais. A gente põe as crianças para arremessar, às vezes a gente faz show, traz o pessoal do circo que faz uma apresentação, às vezes, o pessoal da Ginástica Rítmica, às vezes a gente traz as equipes de base das escolinhas para fazer 10 minutinhos de jogo.

Apesar dos esforços, o dirigente B reconhece que as ações eram muito tímidas e mereciam ser mais bem desenvolvidas, um campo a ser melhor explorado.

Existiam outros pontos que deveriam ser melhorados. A estrutura do ginásio precisava ser revista e modernizada para proporcionar maior conforto e comodidade para os torcedores.

O dirigente A alerta que:

[...] dentro do ginásio tem muita coisa que seria necessário melhorar. Iluminação, limpeza, até cadeiras, porque tem que sentar no cimento e como tem muito pássaro, pombinha, dentro do ginásio. É impossível se manter limpo. A Prefeitura [de Londrina] tá tentando colocar alambrados em volta, para ver se 
diminui a presença de pássaros dentro do ginásio, mas a comodidade é somente na localização. Falta muita coisa, falta estrutura para melhorar o ginásio.

Porém, também, existiam fortalezas a serem ressaltadas. O torcedor que ia de carro para o ginásio encontrava um amplo estacionamento na frente e nos arredores do Ginásio Moringão. Segundo o dirigente A, o Ginásio de Esportes Moringão, onde o time de Londrina sedia seus jogos localiza-se na área central da cidade.

$\mathrm{O}$ dirigente A relata ainda que a segurança era outro dos pontos fortes da estrutura armada para a realização dos jogos. Seis a dez homens eram contratados para fazer a segurança dentro do ginásio, dois para vigiar a portaria, e também se costumava contatar a Polícia Militar para colaborar com dez homens na segurança. Mesmo com o otimismo do dirigente A e da ausência de relatos de ocorrências graves, parece difícil acreditar que esse número de policiais pudesse evitar uma possível confusão generalizada.

É importante ressaltar o pensamento de Kearney, segundo o qual a base dos ganhos de cada equipe virá sempre do torcedor fiel e tradicional. Nesse sentido, a equipe de Londrina parece estar bem servida. O primeiro indício encontrava-se no fato de ter em seus jogos uma das maiores médias de público do CNBM há vários anos. O Relatório de Mídia dos campeonatos nacionais de 2003 e 2004 apontam as equipes de Uberlândia, Araraquara, Goiás, Londrina, Mogi das Cruzes, Ribeirão Preto e Franca como aquelas que obtinham em seus jogos as maiores médias de público (CBB, 2003; CBB, 2004).

O segundo indício residia no envolvimento que a torcida tinha com os interesses do LBC. Segundo o dirigente D:

[...] ela acompanha, ela é participativa, ela é apaixonada. Ela veste a camisa. As pessoas diariamente perguntam. Eles querem saber o que está acontecendo diariamente com o basquete. E tudo isso, o melhor de tudo isso, é que é espontâneo. Essa mobilização do torcedor é espontânea.

Dirigente A recorda que os torcedores eram de origens diversas, mas que as classes A e B eram as que mais compareciam aos jogos, apesar de no aspecto geral ser bem diversificado. Apesar dessa predominância da elite na platéia, os dirigentes já tentaram uma estratégia para popularizar a modalidade. Em 2005, o valor dos ingressos foi reduzido para 4 reais a entrada inteira e 2 reais a meia-entrada. Essa 
diminuição no valor do ingresso ia de encontro aos dados da pesquisa de Kazsnar que salientava o baixo poder aquisitivo dos brasileiros. No entanto, Agassi (2005) comenta que assim o lucro com renda de jogos acabava sendo irrisório.

As diferenças das realidades americanas e brasileiras são gritantes, pois se o estudo de Kearney apontou que em 2001 cerca de 45\% das receitas do esporte profissional eram provenientes da venda de ingressos, em Londrina, mesmo com uma das melhores médias de público do CNBM, os valores discriminados no Relatório de Contrapartida do LBC em 2004, apresentaram uma receita anual vinda dos ingressos de apenas $\mathrm{R} \$ 15.486,00$.

Dessa maneira, considerando que, naquele tempo, as despesas anuais do LBC beiravam 700 mil reais a receita com a venda de ingressos equivalia a pouco mais de $2 \%$, ou seja, um percentual 22 vezes menor que o encontrado pelos estudos de Kearney (2003) com os esportes profissionais americanos (HIRATA, 2005).

Talvez as realidades econômicas distintas expliquem essas diferenças, principalmente se considerarmos a ótica do estudo de Kasznar, que ainda que diga respeito ao Voleibol, parece ter compatibilidade elevada com o caso do basquetebol. Os dirigentes precisam pensar sobre a exploração da venda de ingressos, já que ela tem essa dimensão no mundo esportivo profissional. No caso do LBC, seria interessante que seus dirigentes analisassem esse meio como um dos potenciais a serem explorados para aumentar a arrecadação de receitas.

A segunda categoria de receitas a ser analisada é a venda de direitos de transmissão. Nesse quesito, o LBC não consegue arrecadar nada, uma vez que os direitos de transmissão do CNBM de 2004 foram pagos pela SPORTV e pela Rede TV à CBB diretamente. O dirigente A comenta que:

[...] automaticamente quando se faz a inscrição no campeonato, o regulamento consta que o clube participante cede à imagem dele, som, voz, imagem para competição e o patrocinador é o Sportv e a Rede TV. Eles dão a transmissão, que automaticamente estão dando para o nosso patrocinador, o retorno de mídia.

Kearney (2003) relata em seu estudo outras plataformas utilizadas pelos times profissionais para viabilizar o comércio de imagens. Entretanto, esta é uma realidade ainda distante do LBC, um momento em que os 
resultados parciais de um jogo de basquetebol do Londrina sejam transmitidos, via sistema instantâneo de mensagens, a pedido de um consumidor, ou que o Moringão esteja estruturado com poltronas conectadas à Internet. Não é possível comprar uniformes ou outros adereços do LBC pela Internet, nem ao menos acessar o site oficial do LBC para encontrar informações básicas como: programação dos jogos, dados dos jogadores e do time e histórico, simplesmente porque esse site nunca existiu.

Se a venda de ingressos dá lucros irrisórios e os direitos de transmissão e imagem não geram nenhuma receita, o financiamento das atividades da equipe de basquetebol de Londrina parece depender quase que exclusivamente dos patrocínios, que é considerada a terceira forma tradicional de aumentar as receitas.

Conforme exposto anteriormente, no Brasil, o poder público patrocina vários clubes e modalidades. O basquetebol de Londrina se encaixa nesse contexto. O LBC teve uma receita de R\$320 mil em 2004, advinda do Fundo Municipal de Incentivo ao Esporte, que é fomentado pela Prefeitura Municipal de Londrina (PML), através da Fundação de Esportes de Londrina (FEL), além de um auxílio estrutural da mesma entidade (DIRIGENTE C, DIRIGENTE A).

Nós fizemos uma coisa mista, de fazer o esporte voltado para a sociedade e não deixando de lado o esporte competitivo, de competição, esporte de rendimento, que em última análise vai representar a cidade. Logicamente destinamos um dinheiro razoável para os esportes de liga, mas que não é suficiente para eles fazerem uma super equipe. Mas, agora como é lei de incentivo a projeto esportivo, também nós não podemos carrear todo o dinheiro. Então o basquete recebeu o maior quinhão (DIRIGENTE C).

Mesmo com esse repasse, o dirigente E questiona alguns posicionamentos da PML, que não facilitava a busca por novos parceiros:

A Prefeitura [de Londrina] não permitia que o segundo patrocinador tivesse mais espaço que ela. As cores do clube tinham que ser as cores da bandeira dela. Determinadas condições do patrocínio da Prefeitura dificultavam novos patrocinadores, e a gente não tinha condição de abrir mão da Prefeitura naquele momento.

Essa crítica é rebatida pelo Dirigente C que argumenta que existem portarias que normatizam a publicidade nos uniformes das equipes que detêm patrocínio da FEL. O dirigente salienta que o município 
por arcar com grande parte dos recursos da equipe de basquetebol tem o direito de ver seu nome e cores no uniforme.

Ciente das limitações do patrocínio público, o dirigente B recorda que a idéia básica ao criar o LBC era gradativamente depender menos do poder público e buscar auxílio através de patrocínios privados. Essa idéia foi parcialmente alcançada, pois, segundo o Relatório de Contrapartida do LBC (2004), a equipe conseguiu diversas parcerias e no ano de 2004 conseguiu um auxílio da comunidade de aproximadamente R\$ 457 mil. Vale ressaltar que essas parcerias, algumas prestadoras de serviços públicos, seriam incapazes de manter as atividades do basquetebol de Londrina isoladamente, ou seja, a ausência dos recursos do poder público inviabilizaria a equipe.

Distintamente do que argumenta Kearney, no Brasil, o patrocínio parece ser a maior fonte de receitas das equipes profissionais, excetuando o futebol, e com um agravante: grande parte desses patrocínios provém de empresas públicas. E como dito anteriormente, a dependência do poder público não aparenta ser uma boa estratégia por colocar o futuro de uma equipe esportiva na mão de dirigentes políticos.

\section{CONCLUSÕES}

Os dados relativos ao basquetebol de Londrina demonstraram que o patrocínio é o mecanismo preponderante na arrecadação de recursos financeiros dessa equipe esportiva profissional. Percebeu-se também uma parcela significativa de recursos públicos, através de fundo de incentivo ao esporte, sem os quais o esporte profissional de Londrina possivelmente não existiria.

Além dessa constatação, o estudo permitiu visualizar a irrisória participação da venda de ingressos na formação dos recursos financeiros dessa equipe e reforçar a teoria que a literatura trazia a respeito da pouca importância que a venda de ingressos tem para os clubes esportivos do Brasil. No caso do basquetebol, a venda de direitos de transmissão não gerou nenhum tipo de receita para os clubes.

Alguns traços da realidade desnudada com o presente estudo, em última instância, apresentam um quadro caótico e com perspectivas limitadas de alterações, que é o quadro do esporte brasileiro. O cenário atual possibilita perspectivar que as entidades ligadas ao esporte profissional que utilizam de patrocínios públicos necessitam caminhar em direção a uma autonomia financeira para não depender de ações políticas. 


\section{REFERÊNCIAS}

AGASSI, G. Lucro com renda de jogos é irrisório. Folha de Londrina, p. 3 Esporte, 6 fev. 2005.

CONFEDERAÇÃO BRASILEIRA DE BASKETBALL, (CBB). Relatório de mídia: 2002. Rio de janeiro CONFEDERAÇÃO BRASILEIRA DE BASKETBALL, (CBB). Relatório de mídia: 2003. Rio de Janeiro . Relatório de mídia: 2004. Rio de Janeiro

HIRATA, E. A organização administrativa de uma equipe profissional de basquetebol: o caso de Londrina (1997-2004). 2005. Dissertação (Mestrado em Ciências Sociais Aplicadas) - Universidade Estadual de Ponta Grossa, Ponta Grossa, 2005.

INSTITUTO BRASILEIRO DE GEOGRAFIA E ESTATÍSTICA. Disponível em <,http://www.ibge.gov.br/home/estatistica/populacao/condicaodevida/indicadoresminimos/tabela3.shtm\# a32>

KASZNAR, I.K. O esporte como indústria: solução para criação de riqueza e emprego. Rio de Janeiro: Confederação Brasileira de Volleyball, 1999.

KEARNEY, A.T. O jogo está começando. HSM Management, v.4, n. 39, 2003.

KFOURI, J. A mídia e o marketing esportivo. In: SEMINÁRIO INDESP DE MARKETING ESPORTIVO. Ouro Preto, 1995. Anais... Ouro Preto: INDESP, 1995.

LONDRINA BASQUETE CLUBE. Projeto apresentado à Fundação de Esportes de Londrina para concorrer ao Fundo de Incentivo ao Esporte: 2003. Londrina 2003

LONDRINA BASQUETE CLUBE. Relatório de contrapartida: 2004. Londrina, 2004

PILATTI, L. A. A lógica da produção do espetáculo: o esporte inserido na indústria do entretenimento. Revista de Economía Política de las Tecnologías de la Información y Comunicación. v. 8, n. 2, 2006.

PRONI, M. W. Marketing e organização esportiva: elementos para uma história recente do esporteespetáculo. Revista Conexões. v. 1, n. 1, 1998. 


\section{Edison Hirata}

Universidade Tecnológica Federal do Paraná - Campus Campo Mourão

Luiz Alberto Pilatti

Universidade Tecnológica Federal do Paraná - Campus Ponta Grossa

\section{Referência do artigo:}

\section{ABNT}

HIRATA, E., PILATTI, L. A. Recursos financeiros públicos e privados em equipes esportivas profissionais: 0 caso do basquetebol de Londrina (1997-2004). Conexões, v.5, n. 2, p. 45-58, 2007.

\section{APA}

Hirata, E., \& Pilatti, L. A. (2007). Recursos financeiros públicos e privados em equipes esportivas profissionais: o caso do basquetebol de Londrina (1997-2004). Conexões, 5(2), 45-58.

\section{VANCOUVER}

Hirata E, Pilatti LA. Recursos financeiros públicos e privados em equipes esportivas profissionais: o caso do basquetebol de Londrina (1997-2004). Conexões, 2007, 5(2): 45-58. 